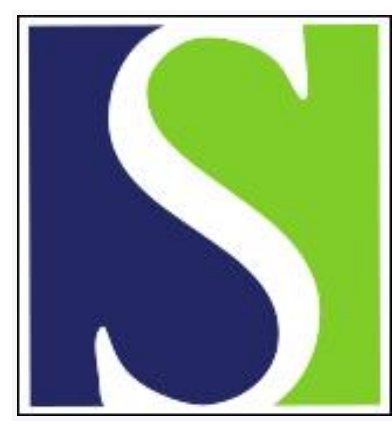

Scand J Work Environ Health 1992;18(5):327-328

https://doi.org/10.5271/sjweh.1568

Issue date: 01 Oct 1992

\section{Severe farmer's lung following a workplace challenge.}

by Kokkarinen J, Tukiainen $\mathrm{H}$, Terho EO

Affiliation: Department of Pulmonary Diseases, Kuopio University Hospital, Finland.

This article in PubMed: www.ncbi.nlm.nih.gov/pubmed/1439661 


\title{
Severe farmer's lung following a workplace challenge
}

\author{
by Jouko Kokkarinen, MD, ${ }^{1}$ Hannu Tukiainen, MD, ${ }^{1}$ Erkki O Terho, MD $^{2}$
}

\begin{abstract}
KOKKARINEN J, TUKIAINEN H, TERHO EO. Severe farmer's lung following a workplace challenge. Scand $J$ Work Environ Health 1992;18:327-8. A severe attack of farmer's lung developed in a dairy farmer after a workplace challenge. The patient showed full recovery after corticosteroid therapy. If a workplace challenge is considered necessary in the diagnosis of farmer's lung, care should be taken to avoid unnecessarily heavy exposure to the offending antigens.
\end{abstract}

Key terms: extrinsic allergic alveolitis, bronchial provocation tests, case report.

Farmer's lung is usually diagnosed on the basis of symptoms, the demonstration of exposure to the offending antigens, chest radiograph findings, and pulmonary function changes (1). In doubtful cases, a histological specimen of the lung or a provocation test may be required. These are not, however, routine diagnostic procedures, and a provocation test has been considered potentially hazardous in the occurrence of farmer's lung $(2,3)$. We present a case in which a severe attack of farmer's lung developed in association with a workplace challenge.

\section{Case report}

In February 1989 a 54-year-old female dairy farmer developed dyspnea on exertion, fever that usually occurred in the evening, and cough. The symptoms lasted for approximately one month and began to improve when the patient was away from the cow barn. When she was initially examined at the hospital in March 1989 , she was asymptomatic. Her chest radiograph was regarded as normal. Spirometry showed mild restriction [forced vital capacity 2.551 ( $77 \%$ of predicted), forced expiratory volume in $1 \mathrm{~s} 2.091$ (78\% of predicted)] and her pulmonary diffusing capacity was normal [transfer factor $7.6 \mathrm{mmol} \cdot \mathrm{min}^{-1} \cdot \mathrm{kPa}^{-1}(100 \%$ of predicted)]. Precipitating antibodies to Thermoactinomyces vulgaris were detected in her serum. The suspicion of farmer's lung arose, but the diagnosis could not be confirmed.

After the patient had recovered she continued to work in the cow barn. She had some nasal discharge and occasional cough. About two years later, symptoms similar to those experienced in 1989 (ie, dyspnea, cough, and fever) developed. Again the symptoms

\footnotetext{
1 Department of Pulmonary Diseases, Kuopio University Hospital, Kuopio, Finland.

2 University of Turku, Turku, Finland.
}

Reprint requests to: Dr J Kokkarinen, Department of Pulmonary Diseases, Kuopio University Hospital, SF-70210 Kuopio, Finland. lasted for about one month and gradually subsided when the patient was away from the cow barn. In the hospital, at the end of March 1991, her chest radiograph and diffusion test yielded normal findings. Her spirometric values showed mild restriction. During the spring, when the patient was on sick leave, she worked twice for a short time in the cow barn, and on both occasions she had fever, cough, and dyspnea in the evening.

Since the diagnostic criteria for farmer's lung were not fulfilled despite a strong suspicion of the disease and repeated investigations, a workplace challenge was finally arranged in the beginning of June 1991. The patient worked in the morning in the cow barn for $2 \mathrm{~h}$ without a personal dust respirator. During that time she handled hay and straw and had no unusual symptoms during the workshift. Three hours after the start of the workshift, dyspnea began, and $1 \mathrm{~h}$ later she had fever. When she came to the hospital that afternoon, she was febrile and had marked dyspnea at rest. Sound crepitations without wheeze were heard from her lungs. The next day a chest radiograph showed widespread nodular interstitial infiltration and some patchy infiltrates at the lung bases. The patient's arterial blood oxygen tension was $8.2 \mathrm{kPa}$ when she was breathing oxygen at $1.51 \cdot \mathrm{min}^{-1}$. Her blood leucocyte count was $16.5 \times 10^{9} \cdot 1^{-1}$ (normal $4-10$ ), and her C-reactive protein level was $183 \mathrm{mg} \cdot 1^{-1}$ (normal $<10$ ). Spirometry showed severe restriction [forced vital capacity 0.951 ( $30 \%$ of predicted) and forced expiratory volume in $1 \mathrm{~s} 0.871$ ( $35 \%$ of predicted)]. Her pulmonary diffusing capacity could not be measured because of the low lung volumes. Three days later the patient was still febrile $\left(38.4^{\circ} \mathrm{C}\right)$, had dyspnea at rest, and crepitations were still audible. Corticosteroid treatment was started at a daily dose of $24 \mathrm{mg}$ of methylprednisolone, and the symptoms began to improve. Corticosteroids were continued for two weeks.

After three weeks the patient's symptoms had improved. The results of the spirometry and the diffusion test were normal. The patient's arterial oxygen 
tension, blood leucocyte count, and C-reactive protein level had normalized. The changes in the chest radiograph had cleared up. In the check-up after two months the patient was asymptomatic and had stopped working in the cow barn.

\section{Discussion}

The internationally accepted criteria for extrinsic allergic alveolitis do not require the use of provocation tests (1). If the criteria are not fulfilled and a confirmed diagnosis is needed (eg, for insurance benefits), additional diagnostic procedures such as provocation tests or lung biopsy can be performed. Otherwise, the adoption of adequate preventive measures should be advised.

A provocation test can be made either in the laboratory setting or in the workplace. In the laboratory a standardized hay exposure or an inhalation challenge with the offending antigen can be performed $(4,5)$. In a study of inhalation provocation tests in the case of bird fancier's lung, mushroom worker's lung, and farmer's lung, the two strongest reactions occurred in two patients tested in the laboratory with the method of natural hay exposure (6). Thus it is possible that the risk of severe reactions is greater in farmer's lung than in other forms of allergic alveolitis. In the workplace exposure test the situation is even less controlled than in the laboratory and may lead to an unnecessarily heavy exposure to the offending antigen. There is also the possibility for a false positive reaction in the provocation test, because systemic reactions to hay exposure have been reported even for healthy volunteers (7). Workplace challenge has been used to confirm the diagnosis of allergic alveolitis when the causative agent is unusual, but there is also a possibility of excessive reaction (8).

Our patient developed a severe attack of farmer's lung in the workplace challenge. She had pronounced dyspnea at rest and needed supplemental oxygen. Major changes were observed in her chest radiograph and pulmonary function. Retrospectively, it is obvious that she had had two episodes of farmer's lung previously, but she had always been admitted to the hospital too late, when she was in the phase of recovery. When the workplace challenge was conducted, the patient had only recently recovered from the last episode. During that time she may have been exceptionally susceptible to the reaction in the challenge.

When a workplace challenge is considered necessary in the diagnosis of farmer's lung, it must be conducted with caution. Care should be taken to avoid unnecessarily heavy exposure to the offending antigen because there is risk of prolonged illness or even permanent changes in lung parenchyma or pulmonary function. If a severe reaction is induced in the challenge, prompt initiation of corticosteroid treatment should be considered (9). We would like to emphasize that both workers and health personnel should be aware of the possibility that allergic alveolitis can occur in work environments with heavy airborne concentrations of organic dusts. This awareness should ensure early diagnostic examination of symptomatic subjects, and such early steps would be the best way to avoid unnecessary provocation tests.

\section{References}

1. Terho EO. Diagnostic criteria for farmer's lung disease. Am J Ind Med 1986;10:329.

2. Terho EO. Extrinsic allergic alveolitis - the state of the art. Eur J Respir Dis 1982;63 supp1 124:10-26.

3. Molina C. Occupational extrinsic allergic alveolitis. Clin Immunol Allergy 1984;4:173-92.

4. Muller-Wening D, Repp H. Investigation on the protective value of breathing masks in farmer's lung using an inhalation provocation test. Chest 1989;95:100-5.

5. Edwards $\mathrm{JH}$, Davies $\mathrm{BH}$. Inhalation challenge and skin testing in farmer's lung. J Allergy Clin Immunol 1981; 68:58-64.

6. Hendrick DJ, Marshall R, Faux JA, Krall JM. Positive "alveolar" responses to antigen inhalation provocation tests: their validity and recognition. Thorax 1980;35: 415-27.

7. Vogelmeier C, Baur X, König G, Fruhman G. Diagnostik der exogen-allergischen Alveolitis: Heustaub-Testungen bei nicht-exponierten Kontrollpersonen. Prax Klin Pneumolol 1987;41:645-6.

8. Kuusisto P, Veneskoski T, Alavaikko M. Työpaikkaaltistus allergisen alveoliitin diagnosoinnissa [A work exposure test in the diagnosis of allergic alveolitis]. Duodecim 1980;96:958-63.

9. Fink JN. The use of bronchoprovocation in the diagnosis of hypersensitivity pneumonitis. J Allergy Clin Immunol 1979;64,Part 2:590-1.

Received for publication: 20 May 1992 